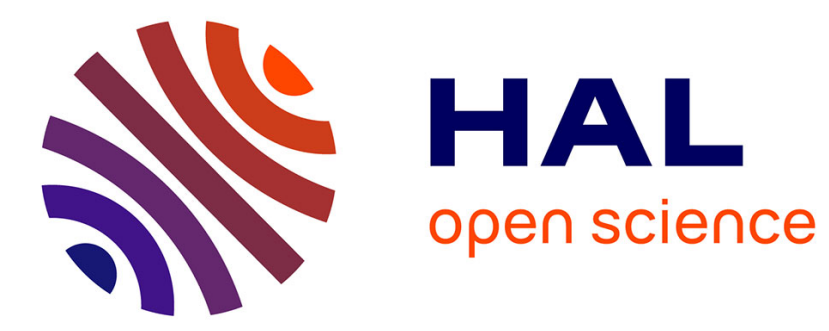

\title{
Mapping surface fluxes using airborne visible, near infrared, thermal infrared remote sensing data and a spatialized surface energy balance model
}

Frédéric Jacob, Albert Olioso, - Xing Fa Gu, - Zhongbo Su, Bernard Seguin

\section{- To cite this version:}

Frédéric Jacob, Albert Olioso, - Xing Fa Gu, - Zhongbo Su, Bernard Seguin. Mapping surface fluxes using airborne visible, near infrared, thermal infrared remote sensing data and a spatialized surface energy balance model. Agronomie, 2002, 22 (6), pp.669-680. 10.1051/agro:2002053 . hal-02674647

\section{HAL Id: hal-02674647 \\ https://hal.inrae.fr/hal-02674647}

Submitted on 5 Nov 2021

HAL is a multi-disciplinary open access archive for the deposit and dissemination of scientific research documents, whether they are published or not. The documents may come from teaching and research institutions in France or abroad, or from public or private research centers.
L'archive ouverte pluridisciplinaire HAL, est destinée au dépôt et à la diffusion de documents scientifiques de niveau recherche, publiés ou non, émanant des établissements d'enseignement et de recherche français ou étrangers, des laboratoires publics ou privés.

$$
\text { Copyright }
$$




\title{
Mapping surface fluxes using airborne visible, near infrared, thermal infrared remote sensing data and a spatialized surface energy balance model
}

\author{
F. Jacob ${ }^{* a, b}$, A. Olioso ${ }^{\text {b }}$, X.F. Gu ${ }^{\text {b }}$, Z. Su ${ }^{\text {c }}$, B. Seguin ${ }^{\text {b }}$
}

a USDA/ARS Hydrology and Remote Sensing Laboratory, Bldg 007, BARC-West, Beltsville, MD 20705-2350, USA

b INRA Climat-Sol-Environnement,

Domaine St Paul, Site Agroparc, 84914 Avignon Cedex 9, France

c Wageningen University \& Research Center, Alterra Green World Research P.O. Box 47, 6700 AA Wageningen, the Netherlands

\footnotetext{
* Corresponding author : Phone: (1) 301-504-6142

Fax: (1) 301-504-8931

Email: fjacob@hydrolab.arsusda.gov
}

Running title: Estimating energy fluxes using a spatialized model 


\begin{abstract}
A spatialized surface energy balance model was validated over the database acquired in the framework of the ReSeDA program. The benefit of the SEBAL model we considered was to compute wind speed and air temperature using the information contained in the spatial variability of convective fluxes. The multitemporal database allowed to perform a validation over cycles of several crops. Problems induced by mixed pixels were reduced using high spatial resolution remote sensing data. We verified the validity of the model basic assumption, i.e. the simultaneous presence of partial areas with very high and very low evaporation rates, and the resulting relation between surface temperature and albedo. Besides, the model provided estimates of wind speed and air temperature close to the field references. The validation of soil heat flux showed the inadequacy of the empirical relationship used through a significant underestimation of the references. The validation of sensible heat flux provided similar results as compared to previous studies that dealt with model validations over databases including numerous situations.
\end{abstract}

Visible, near infrared, thermal infrared remote sensing / surface energy balance / spatialized procedure and spatial variability / SEBAL 
Titre: Cartographie des flux d'énergie à partir de données télédétectées visible, proche infrarouge, infrarouge thermique, et d'un modèle spatialisé

Résumé - Nous avons validé un modèle de bilan d'énergie de surface en utilisant la base de données ReSeDA. L'intérêt du modèle SEBAL était d'estimer la vitesse du vent et la température de l'air à partir de l'information contenue dans la variabilité spatiale des flux convectifs. La base de donnes multitemporelle permettait d'effectuer une validation en considérant les cycles de plusieurs cultures. Les problèmes dus aux pixels mixtes étaient réduits par l'utilisation de données télédétectées à haute résolution spatiale. Nous avons pu vérifier la validité de l'hypothèse de base du modèle, i.e. la présence simultanée de zones très évaporante ou peu évaporante, ainsi que la relation entre albedo et température qui en résulte. De plus, le modèle a fourni des estimations de la vitesse du vent et de la température de l'air proche des mesures de référence. La validation du flux de chaleur dans le sol a montré que la relation empirique générait une sous-estimation importante. La validation du flux de chaleur sensible a fourni des résultats comparables à ceux rencontrés dans la littérature et concernant la validation de modèles sur des bases de données incluant de nombreuses situations.

télédétection visible, proche infrarouge, infrarouge thermique / bilan d'énergie de surface / méthode spatialisée et variabilité spatiale / SEBAL 


\section{Introduction}

Surface energy fluxes characterize the radiative, conductive and convective exchanges between soil, surface and atmosphere. Since these exchanges are strongly linked to water and mass transfers, their knowledge is of prime interest for agronomy when dealing with crop monitoring and yield prediction [60], hydrology when characterizing the water cycle [53], and meteorology when estimating the boundary conditions of atmospheric numerical models $[43,17]$. The required accuracy may vary from an application to another. [59] proposed that an absolute accuracy about $\pm 50 \mathrm{~W} . \mathrm{m}^{-2}$ for the sensible heat flux is a good compromise for several applications. Many of the land surface properties that drive energetic transfers at the soil - vegetation - atmosphere interface can be mapped using remote sensing: surface temperature [5, 57], albedo [61, 69, 31], Fractional Vegetation Cover and Leaf Area Index [14, 13, 68] and soil moisture [55, 9]. These variables can next be used as input for models that describe the mechanisms of energy transfers $[42,58,49,9]$.

Several algorithms were developed this two last decades to estimate surface energy fluxes from remote sensing according to the available information. These algorithms may use empirical models such as the simplified relationship [16, 10], mechanistic models such as Soil - Vegetation - Atmosphere Transfer models [52, $21,49]$, or intermediate approaches based on surface energy balance models [36, $34,27]$. Regardless of chosen algorithm, one of the main difficulties is the estimation of variables that can not be obtained directly from remote sensing. This is particularly true for meteorological variables such as air temperature and wind speed, which are required in almost every approaches. A possible solution consists in using measurements provided by micrometeorological stations and meteorological networks $[41,34]$. However, these data may be not representative of the investigated area because of the spatial variability of the atmospheric variables in 
relation with the variability of surface characteristics [15].

To avoid the use of ancillary information that can have a poor spatial representativeness, other algorithms were developed by considering differential approaches. Using the temporal variation of the remotely sensed surface temperature while accounting for the evolution of the boundary layer eliminates the need for air temperature measurement and reduces the sensitivity to data inaccuracy $[19,1,39]$. However, such a temporal approach requires a continuous acquisition of surface temperature, and therefore the use of geostationary satellites with coarse spatial resolutions. When focusing on sun-synchronous satellites with higher ground resolutions, a solution consists in considering the spatial variability depicted by the observed surfaces according to their energetic status. Indeed, it is possible to use relations between remote sensing variables such as surface temperature and either NDVI $[12,21]$ or albedo $[40,66]$. To reduce the model sensitivity to data inaccuracy, $[21,11]$ proposed to rescale the simulated remote sensing variables. With the same purpose, $[26,2]$ proposed to calibrate air temperature versus remotely sensed surface temperature.

The Surface Energy Balance Algorithm for Land model (SEBAL, [3]) is a model that considers the spatial variability induced by hydrological and energetic contrasts. The main feature of this surface energy balance model is to retrieve at the same time atmospheric variables (wind speed and air temperature) and energy fluxes using the information contained in the spatial variability of convective fluxes. Such an approach relies on the assumption of the simultaneous presence of dry areas and wet areas over the study site. By computing the other required variables using empirical or semi-empirical relationships, the model was presented by its author as an original tool that does not require any ancillary information. The model was validated by $[4,23,24]$ through hydrological indicators. However, 
there is at the present time no validation dealing with the estimates of instantaneous energy fluxes and especially the estimates of wind speed and air temperature that are the original points of the model.

In the framework of the ReSeDA (Remote Sensing Data Assimilation) program, a unique database was collected throughout one year, including satellite and airborne remote sensing data, as well as field measurements of surface properties and meteorological variables. Such a database provided the opportunity to assess the original points of SEBAL by validating the resulting estimates. Moreover, the ReSeDA database allowed to perform a validation accounting for several meteorological and land use situations, while problems induced by mixed pixels were reduced using high spatial resolution remote sensing data. This paper reports the results we obtained when validating the SEBAL model over the ReSeDA database. After the presentation of the data, of the model and of the methods used to compute the model inputs, we discuss the SEBAL results, both on its key points and on the surface energy flux estimates.

\section{Data acquisition and preprocessing}

\subsection{The ReSeDA Experiment}

The ReSeDA experiment lasted from December 1996 to November 1997, in the south east of France (N 43 $47^{\circ}, \mathrm{E} 4^{\mathrm{o}} 45^{\prime}, 10 \mathrm{~m}$ above sea level, Mediterranean climate). The experimental site was a $5 \times 5 \mathrm{~km}^{2}$ agricultural region with sunflower, wheat, corn, grassland and alfalfa fields about $200 \times 200 \mathrm{~m}^{2}$. Detailed descriptions of the experiment are6 given by [54] and [51]. Among the numerous satellite, airborne and field measurements collected, the main data used in this study were 1) airborne measurements acquired over the Visible - Near InfraRed and Thermal InfraRed domains (Vis - NIR - TIR), 2) in-situ TIR data, and 3) field measurements 
of both meteorological variables and surface energy fluxes. We present here an overview of the data acquisition and preprocessing. Complete descriptions of the procedures are given by $[29,20,22,48]$.

\subsection{Field data}

Field measurements were performed on seven points located on alfalfa, wheat, and sunflower crops [48]. Incoming solar radiation was measured on a meteorological station located at the center of the site using a pyranometer. Two other measurements of incoming solar radiation were performed on different locations and provided very similar results. The meteorological station also provided measurements of incoming thermal radiation from a pyrgeometer. Instrumentations at the seven locations were installed at least 100 meters far from upwind edges. Surface brightness temperature over the [8-14] $\mu \mathrm{m}$ spectral range was measured using HEIMANN KT 15 and 17 radiometers. The measured surface fluxes were the four components of surface energy balance, i.e. net radiation, soil heat flux and both sensible and latent heat fluxes. Net radiation was measured using differential pyrradiometers. Soil heat flux was estimated using heat flow transducers installed at a $5 \mathrm{~cm}$ depth. These measurements were corrected by the change of thermal storage from the transducer level to the surface. Four replications were used for each site. Sensible and latent heat fluxes were computed from 2 level measurements of air temperature and relative humidity using the Bowen ratio method. Sensible heat flux was also measured occasionally using one-dimension eddy covariance systems. All the data mentioned here were acquired with a 15 second time step and a 20 minute period averaging.

The instruments we used were calibrated before and after the experiment. The laboratory calibration of the HEIMANN radiometers suggested an accuracy better than $1{ }^{\circ} \mathrm{C}$. Two other kinds of nadir surface brightness temperature measurements 
over the [8-14] $\mu \mathrm{m}$ spectral range were occasionally performed using CIMEL and EVEREST radiometers. The inter-comparison of the three data sets showed good agreement, with a ARMSD ${ }^{1}$ between 0.2 and $0.8{ }^{\circ} \mathrm{C}$. The pyrradiometer intercalibration showed that the net radiation measurements were accurate within $8 \mathrm{~W} \cdot \mathrm{m}^{-2}$. No accuracy was proposed for the procedure used to compute soil heat flux. Therefore, we set this accuracy to a value mentioned in the literature by a previous study that used the same procedure [62]. It was about $40 \mathrm{~W} \cdot \mathrm{m}^{-2}$. Moreover, an analysis of the data collected around solar noon indicated a spatial variability over the four replications of a given site ranging between 15 and $40 \mathrm{~W} \cdot \mathrm{m}^{-2}$. The inter-comparison of the two convective flux data sets showed significant differences. Data analysis emphasized severe instrumental troubles on the Bowen ratio method. The comparison against eddy correlation method provided an ARMSD about $75 \mathrm{~W} \cdot \mathrm{m}^{-2}$. The data were then filtered to remove encountered problems. A smoothing procedure applied to the Bowen ratio calculations decreased this ARMSD to $55 \mathrm{~W} \cdot \mathrm{m}^{-2}$ [48].

\subsection{Airborne data}

Airborne remote sensing data were acquired using two sensors set up aboard a plane: the Polarization and Directionality of Earth Reflectance (PolDER) imaging radiometer [18] and an INFRAMETRICS 760 thermal infrared video camera [28]. Both the instruments flew on clear sky days approximately one or two times per month at a $3000 \mathrm{~m}$ altitude yielding a $20 \mathrm{~m}$ nadir spatial resolution. Four flight lines were parallel to the solar principal plan, and one perpendicular. These five lines were completed within 45 minutes centered around solar noon.

The PolDER imaging radiometer provided Vis-NIR measurements over four

\footnotetext{
${ }^{1}$ The ARMSD (Absolute Root Mean Square Difference) is the mean quadratic error between either predicted or observed variables. The RRMSD (Relative Root Mean Square Difference is the ratio of the ARMSD to the mean value of either the predicted or the observed variables.
} 
bands centered at $443,550,670,865 \mathrm{~nm}$, each $40 \mathrm{~nm}$ wide. Zenith view angle ranged between 0 and $50^{\circ}$. Data were radiometrically corrected in a similar way than that used by [38]. The sensor calibration was performed by the Laboratoire d'Optique Atmophérique (Lille, France) three times: before, during and after the experiment. It accounted for ambient temperature, dark current, optic transmission, and the relative sensitivity of the CCD matrix detectors. Atmospheric corrections were performed using the SMAC algorithm [56] along with climatological data and field measurements of atmospheric variables. The images were geometrically matched according to a Lambert II projection using data acquired by both a global positioning system and a gyroscopic central unit set up aboard the plane. The Lambert II projection corresponded to a $20 \mathrm{~m}$ spatial sampling meshgrid. The preprocessing described here provided finally a data base of sampled BRDF (Bidirectional Reflectance Distribution Function), i.e a pixel by pixel set of measurements of the reflected solar energy in a selection of viewing directions for each PolDER waveband.

The INFRAMETRICS 760 thermal video camera provided TIR measurements over the [7.25-13.25] $\mu \mathrm{m}$ range with view zenith angle ranging from 0 to $40^{\circ}$ using a wide-angle lens. The data were collected on a video tape with a $25 \mathrm{~Hz}$ frequency, and numerized with a $1 \mathrm{~Hz}$ frequency (1 image every 25$)$. The sensor was instrumentally characterized once after the experiment. This characterization accounted for the influence of ambient temperature on the sensor radiometric sensitivity, and for both the directional sensitivity and the geometrical distortions induced by the use of the wide-angle lens. The atmospheric corrections were performed using the radiative transfer code MODTRAN 3.5 [8] along with its climatological database and radio-soundings launched from a meteorological station located at $30 \mathrm{~km}$ toward the west of the experimental site. The images were geometrically matched ac- 
cording to the LAMBERT II projection mentioned previously. The registration was performed using an auto-correlation technique along with ground control points selected from a reference map. All these preprocessing are described in details by [29] and [22]. They provided a data base of multidirectional surface brightness temperature estimates.

The validation of these airborne surface brightness temperature estimates was performed averaging both field and INFRAMETRICS 760 measurements over the period of the airborne data acquisition. This choice was driven by the temporal features of the two data sets. Indeed, the field data were $20 \mathrm{mn}$ averaged measurements whereas the airborne images were instantaneous (25 images/second) and spread over 45 minutes to cover the whole site. To avoid angular effects, we selected airborne data corresponding to a view zenith angle lower than $20^{\circ}$. It was shown that the field references were overestimated with a $7{ }^{\circ} \mathrm{C} \mathrm{ABias}{ }^{2}$. This emphasized that the laboratory calibration was not accurate enough since it did not account for the influence of the experimental environment on the sensor response. Therefore, an inflight calibration was performed using a linear relationship between field and airborne data for each flight. The daily RMSE after recalibration ranged from 0.2 to $0.8^{\circ} \mathrm{C}$.

\section{The model}

The SEBAL version we used was an improved variant proposed by $[63,64]$ to solve an ill posed problem in the former version developed by [3]. In this improved variant, the regional resistance for heat is determined using the potential air temperature at the blending height that is obtained by either Numerical Weather Prediction

\footnotetext{
${ }^{2}$ The ABias (Absolute Bias) is the averaged difference between either predicted values, either observed values, or predicted and observed values. The RBias (Relative Bias) is the ratio of the ABias to the average of respectively either the predicted values, either the observed values, or the observed values.
} 
models or radio-soundings. As mentioned previously, the original point of SEBAL is to compute wind speed and air temperature at reference level using the information contained in the spatial variability of convective fluxes. The model is supplied with maps of albedo, NDVI (Normalized Difference Vegetation Index), surface radiometric temperature, solar and thermal incoming radiations. From these maps, SEBAL computes at the same resolution and at the same time instantaneous estimates of surface properties, wind speed, air temperature and energy fluxes. These computations are performed using both semi-empirical relationships and simplifications of energy balance formulation over dry areas (no evapotranspiration) and wet areas (no sensible heat transfer). The well known evolution of surface temperature $T_{s}$ versus albedo $\alpha_{s}[6,40,66]$ is used to both verify the existence of hydrological contrasts and allocate dry and wet areas. These partial areas are discriminated using an albedo value that corresponds to the maximum temperature of the concave relation $T_{s}=f\left(\alpha_{s}\right)$. Albedos lower than this threshold value belong to evaporative areas, the highest evaporation rates occurring for the lowest temperatures. Albedos higher than this threshold value correspond to dry areas with very low evaporation rate. In the following paragraph, we give an overview of the model. Detailed descriptions can be found in $[3,63,64]$, as well as in appendix I.

Net radiation $R_{n}$ is computed in a classical way from solar and thermal incoming radiations, albedo, broadband emissivity and surface radiometric temperature. Broadband emissivity over the [3-100] $\mu \mathrm{m}$ spectral range is assumed to be close to mean emissivity between 8 and $14 \mu \mathrm{m}$, which is deduced from NDVI using a logarithmic shaped empirical relationship calibrated by [65] in Savannah environment. Soil heat flux $G_{0}$ is expressed as a fraction of net radiation. The ratio $G_{0} / R_{n}$ is a semi-empirical function expressed as the product of two terms. The first term depends on surface radiometric temperature, instantaneous and daily albedo and 
corresponds to the ratio $G_{0} / R_{n}$ for a bare soil. The second term depends on NDVI and corresponds to the extinction of the incident solar radiation by the canopy. This semi-empirical formulation was calibrated by [3] using several data sets collected over stubble, alfalfa, bare soil, wheat, cotton and soybean. The proposed accuracy is about $0.04 \times R_{n}$. The sensible heat flux is expressed using a bulk resistance approach. Its calculation requires three steps:

- First, roughness length for momentum is deduced from NDVI using an exponential shaped empirical relationship calibrated by [3] over a data set collected in a Mediterranean semi-arid region. Roughness length for heat is set to $1 / 10$ times roughness length for momentum $\left(k B^{-1}=2.3\right)$.

- Second, a mean value of wind speed at the atmospheric reference level is calculated from the aerodynamic properties of an effective layer between the surface and the blending height. The sensible heat transfer through this layer is characterized aggregating surface temperature, roughness lengths and sensible heat flux ( $H \sim R_{n}-G_{0}$ ) over the dry areas allocated from the surface temperature versus albedo diagram. The air temperature at the top of the layer is given by radiosonde since the atmosphere is supposed to be homogenized at the blending height. The aerodynamic properties of this layer are estimated inverting the sensible heat flux expression, and next used to compute wind speed.

- Third, the difference between surface and air temperature is linearly related to surface temperature: $T_{s}-T_{a}=a T_{s}+b$. The linear relationship is calibrated inverting the sensible heat flux over both wet areas $\left(T_{s}-T_{a} \sim 0\right)$ and dry areas $\left(H \sim R_{n}-G_{0}\right)$. These areas are selected considering respectively the minimum and maximum temperatures over the study site. [3] 
emphasized that this differential approach reduces the consequences of aerodynamic temperature inaccuracy on sensible heat flux estimation.

Finally, the latent heat flux is computed as surface energy budget residue.

\section{Computing model inputs from Vis NIR TIR data}

Both albedo and NDVI were derived from the multidirectional Vis-NIR data provided by PolDER. The derivation of albedo was presented in details by [31, 32]. It combined the determination of hemispherical reflectance and the estimation of the integrated value of albedo over the whole solar spectrum. The determination of the hemispherical reflectance from the angular sampling provided by the PolDER data set was performed using the Li-Ross BRDF model [67]. The integrated value of albedo over the whole solar spectrum was expressed as a linear combination of the hemispherical reflectance in the PolDER wavebands. The absolute accuracy of the PolDER albedos was about 0.0188 , which corresponded to a relative accuracy about $9 \%$ [31, 32]. NDVI was computed considering nadir reflectance extrapolated by the BRDF model. Daily albedo was calculated from the diurnal course of albedo, the latter being derived from the BRDF model. A detailed description of the daily albedo calculation is given by [30].

Surface brightness temperature was derived from the multidirectional TIR data acquired using the INFRAMETRICS 760. First, we considered the data acquired with a view zenith angle lower than $20^{\circ}$ since no operational model was available to process the multidirectional information. Second, we computed an averaged value over the data acquisition period (approximately 45 minutes) in order to account for the temporal evolution of surface temperature between the first and the last image acquisition. The investigations of [22] about both the temporal and directional normalizations of the measurements should be used in the future to get 
a better surface temperature estimation. Radiometric temperature was deduced from brightness temperature, emissivity and incoming atmospheric thermal radiation over the INFRAMETRICS 760 spectral range. The emissivity was calculated from NDVI using the empirical relationship mentioned previously. The incoming thermal radiation was expressed as a function of air temperature and air emissivity. Air emissivity was computed in the same way than that used by [46]. Atmospheric radiance was deduced from air temperature using a polynomial relationship that accounted for the INFRAMETRICS 760 spectral response.

The incoming solar and thermal radiations were assumed to be homogeneous over the whole site since 1) the dimensions of the site were about $5 \times 5 \mathrm{~km}^{2}$, and 2) the field measurements of solar radiation over three different locations were very close. Therefore, the two quantities were computed from the measurements provided by the meteorological station. To be consistent with the method used to calculate surface radiometric temperature, these measurements were averaged over the period of the airborne data acquisition, the coefficient of variation ${ }^{3}$ being about $3 \%$.

We should note that the data acquired over the mountain chain located at the south of the study area were removed since the algorithms used to compute the model inputs were not designed for inclined areas. Moreover, we removed the $500 \mathrm{~m}$ width band surrounding the study area since the corresponding surfaces were not as well directionally characterized as the center of the area. Indeed, as a consequence of the flight line configuration, the angular distribution of the observations over these surfaces was located in a portion of the hemisphere.

\footnotetext{
${ }^{3}$ The coefficient of variation is defined as the ratio of the standard deviation to the mean value.
} 


\section{Assessing the model performances}

The data set acquired during the ReSeDA experiment allowed to assess several steps of the model. First, we verified the basic assumption about the hydrological contrast, i.e. the simultaneous presence of wet areas and dry areas, and the resulting relation between surface temperature and albedo. Second, we evaluated the estimates of roughness length for momentum, wind speed, and air temperature. Third, we assessed the validity of the surface energy flux estimates. Most of these investigations consisted in comparing SEBAL outputs against field measurements. In order to be consistent on the temporal aspect, the field measurements were averaged over the period of the airborne data acquisition.

\subsection{Assessing the model assumptions}

To verify the existence of the relation between albedo and surface temperature, we used the following procedure. For a given day, we computed both a surface radiometric temperature mean value and the corresponding standard deviation for each albedo class between 0.05 and 0.4 by step of 0.002 . In a first time the relation was noisy, which could be explained by the combination of spatial variability and registration inaccuracy. This possible effect was assessed by applying a mask over field borders. The noise previously observed was significantly reduced, which emphasized the sensitivity of the method to the registration accuracy when using high spatial resolution data. An example of the $T_{s}\left(\alpha_{s}\right)$ we obtained is given in Figure 1. The positive derivative of surface temperature as a function of albedo is explained by dominant evaporative processes and corresponds to pixels located on evaporative surfaces, i.e. wet bare soil and vegetative areas. The negative derivative is explained by dominant radiative processes and corresponds to pixels located on dry areas, i.e dry bare soils or senescent vegetation. This relation was observed 
for each day of the experiment. Such results indicated the presence of hydrological contrasts over the ReSeDA experimental site, even on days preceded by rainy events. We observed large standard deviation values of surface radiometric temperature for each albedo class that could be explained by the natural variability of the observed surfaces. This was already observed by [3]. From curves as that displayed on Figure 1, pixels corresponding to radiative (respectively evaporative) branch were allocated to dry (respectively wet) areas.

[Figure 1 about here.]

\subsection{Validating the intermediary variables}

Next, we validated the intermediary variables computed by SEBAL, i.e. roughness length for momentum, wind speed and air temperature. The estimates of roughness length $z_{0 m}$ were compared against field measurements deduced from canopy height $h_{c}$ using the classical rule of thumb $z_{0 m}=0.13 \times h_{c}$. The ARMSE ${ }^{3}$ between field and model estimates was about $0.104 \mathrm{~m}$, which corresponded to a RRMSE ${ }^{4}$ of $148 \%$. According to the sensitivity study performed by [50], a relative inaccuracy of $150 \%$ on roughness lenght induced a relative error lower than $20 \%$ on sensible heat flux regardless of $k B^{-1}$ value, when considering a wind speed lower than $10 \mathrm{~m} \cdot \mathrm{s}^{-1}$, and a difference between surface and air temperature lower than $15^{\circ} \mathrm{C}$. Such a relative error corresponded to an absolute error of $30 \mathrm{~W} \cdot \mathrm{m}^{-2}$ according to the mean value of the $H$ field data we used as references, i.e. $170 \mathrm{~W} . \mathrm{m}^{-2}$. The validation results showed the inadequacy of the empirical relationship that expresses roughness length as an exponential function of NDVI. For instance, we noted a significant overestimation when considering the alfalfa crop, which was

\footnotetext{
${ }^{4}$ The ARMSE (Absolute Root Mean Square Error) is the mean quadratic error between predicted and observed variables. The RRMSE (Relative Root Mean Square Error) is the ratio of the ARMSE to the average of the observed values.
} 
explained by high NDVI values and low canopy height throughout the experiment. Similarly, [37] showed that the model provided values 10 times lower than field references over a wheat crop in the senescent phase. They explained this by a decrease of NDVI whereas the canopy kept the same architecture and therefore the same aerodynamic properties. However, we did not perform a calibration by considering crop type and crop phenology since the scope of this study was to validate the model in its original configuration.

The model wind speed estimates were validated against $i n$-situ measurements collected by the meteorological site at the center of the study. The comparison showed that the simulated values were close to the references, with an ARMSE about $0.9 \mathrm{~ms}^{-1}$ and a correlation coefficient of 0.85 (see Figure 2). This showed that the model provided good estimates of wind speed although the resulting inaccuracy on sensible heat flux could be significant at low wind speed values. However, an analysis of the wind speed data collected over the seven location at a $2 \mathrm{~m}$ height showed a spatial variability of $1.1 \mathrm{~m} . \mathrm{s}^{-1}$. This suggested that using the SEBAL computation was not less accurate than using a uniform value from meteorological network since the resulting error was similar. The validation of the estimated air temperature against field measurements showed that the model provided results close to references, with a ARMSE about $2{ }^{\circ} \mathrm{C}$ and a correlation coefficient of 0.96 (see Figure 3). This showed that the assumption of a linear relationship between surface and air temperature was valid and that it was possible to calibrate this relation using the spatial variability over the study site. One should note that an inaccuracy about $2{ }^{\circ} \mathrm{C}$ can generate significant uncertainties on sensible heat flux, i.e. from 30 to $100 \mathrm{~W} \cdot \mathrm{m}^{-2}$ for aerodynamic resistances of 80 and $20 \mathrm{~s} . \mathrm{m}^{-1}$ respectively. However, the spatial variability depicted by air temperature maps was up to $15^{\circ} \mathrm{C}$, which emphasized the benefit of this approach as compared to those 
using meteorological data located on a given point.

[Figure 2 about here.]

[Figure 3 about here.]

\subsection{Validating surface energy fluxes}

The last step of this study was the validation of energy flux calculated by the model. An overview of the results for the four components of surface energy balance is given in Table 1. Figure 4 displays the comparison for net radiation. It was shown that the model provided estimates close to field measurements, with an ARMSE of $20 \mathrm{~W} \cdot \mathrm{m}^{-2}$. Such an error was low as compared to results reported in previous studies when considering similar approaches (ARMSE ranging between 30 and $\left.60 \mathrm{~W} \cdot \mathrm{m}^{-2},[42,36]\right)$. This was ascribed to the accuracy on albedo estimates that was about 0.0188 in absolute or $9 \%$ in relative. The comparison between measured and estimated values of soil heat flux depicted a large discrepancy with a significant underestimation of the field references (Figure 5). The spatial variability of $G_{0}$ (up to $40 \mathrm{~W} \cdot \mathrm{m}^{-2}$ as mentioned in Section 2.2) combined with the difference between the spatial representativeness of the two data sets could partially explain this result. Moreover, the ARMSD corresponded to classical values related in the literature when using this kind of formulation [35, 33], whereas similar results were also obtained over the ReSeDA data set when using more accurate approaches such as SVAT models that describe subsurface heat and water transfers [47]. Nevertheless, the underestimation trend led us to suspect the empirical relationship and especially its calibration. Indeed, the data set [3] used to calibrate the $G_{0} / R_{n}$ ratio could include different situations than those occurring during the ReSeDA experiment. Since knowledge of soil heat flux is important to estimate the available energy for convective fluxes, we compared the model and in-situ estimates of 
$R_{n}-G_{0}$ (see Figure 6). The overestimation on the available energy resulting from soil heat flux underestimation was about $45 \mathrm{~W} \cdot \mathrm{m}^{-2}$. The validation of sensible heat flux showed a significant discrepancy between observed and predicted values (see Figure 7). The errors on model estimates could be explained by the combinations of several factors, i.e. the uncertainties on the estimates of roughness length, emissivity, wind speed, air temperature, soil heat flux, and $k B^{-1}$ parameter. However, such an error was similar to those reported in the literature when validating models over databases that included numerous and various situations [44, 33, 70, 1, 45]. Besides, similar results were obtained by [25] when validating a microscale flux aggregation model over the same database. Finally, the validation of latent heat flux also showed a significant discrepancy with an overestimation trend (see Figure 8). The latter was ascribed to the underestimation of soil heat flux since latent heat flux was calculated as the residue of surface energy balance.

[Table 1 about here.]

[Figure 4 about here.]

[Figure 5 about here.]

[Figure 6 about here.]

[Figure 7 about here.]

[Figure 8 about here.]

The results we obtained when validating the SEBAL model considering the intermediary variables led us to conclude that the interesting points of the model points, i.e. the computation of wind speed and air temperature, provided satisfactory results. On the other hand, the validation of convective fluxes showed significant discrepancies that were ascribed to inaccuracies on the intermediate variables 
such as soil heat flux, roughness length, $k B^{-1}$ parameter, wind speed and air temperature. A better understanding of the consequences of these inaccuracies requires a sensitivity study. Indeed, some variables are used at different stages during the simulations, such as soil heat flux that is required for both wind speed and air temperature calculations. This induces probably errors compensations and / or additions that have to be assessed. Finally, we should note that the SEBAL outputs were maps of surface energy fluxes at a $20 \mathrm{~m}$ spatial sampling (see Figure 9). They depicted a significant spatial variability inside heterogeneous fields that can reach $50 \mathrm{~W} . \mathrm{m}^{-2}$, and a pattern on the larger scale corresponding to the whole site. This emphasized the benefit of using high spatial resolution remote sensing data. After improvements of the model weaknesses to get more accurate maps, a interesting database will be available to address the scaling issue.

[Figure 9 about here.]

\section{Conclusion}

The objective of these study was to validate a spatialized surface energy balance model over the database acquired in the framework of the ReSeDA program. The main benefit of the SEBAL model we used was to compute wind speed and air temperature using the information contained in the spatial variability of convective fluxes. This relies on the assumption of simultaneous presence of dry and wet areas. Using the multitemporal ReSeDA database, it was possible to perform a validation over the whole cycle of several crops. Moreover, problems induced by mixed pixels were reduced using high spatial resolution remote sensing data. The numerous field data collected allowed to perform a validation of the model through the energy fluxes comparisons, but especially on its key points. It was shown that the assumption of the model related to the existence of hydrological 
contrasts and the resulting evolution of surface temperature versus albedo was verified. Moreover, the model estimates agreed with the field references when validating wind speed and air temperature. However, we noted a significant underestimation of soil heat flux that required a reconsideration of the empirical relationship used by the model. The large discrepancy observed when validating the convective fluxes were ascribed to the inaccuracies on intermediate variables. Nevertheless, the corresponding error was common as compared to validations over multitemporal databases that included numerous surface and micrometeorological situations. Since the framework of the model might induce some error compensations and / or additions, a sensitivity study is further required to assess the consequences of inaccuracies on intermediate variables. This will allow to evaluate the benefit of estimating air temperature by using such a differential approach that is assumed to minimize input errors.

\section{Appendix I: the SEBAL model}

The SEBAL model is supplied with maps of instantaneous albedo, NDVI and radiometric temperature. It provides estimates at the same time than data acquisition of the following variables: mean value of wind speed over the study area, maps of air temperature and surface energy fluxes at the same resolution.

\subsection{Estimating the net radiation and the soil heat flux}

Net radiation is the algebraic sum of short-wave and long-wave radiative fluxes:

$$
R_{n}=\left(1-\alpha_{s}\right) R_{g}+\varepsilon_{s} L_{a}^{\downarrow}-\varepsilon_{s} \sigma T_{s}^{4}
$$

where albedo $\alpha_{s}$ is the fraction of incoming solar radiation $R_{g}$ reflected by the

surface, $L_{a}^{\downarrow}$ is the atmospheric downwelling radiation, $\varepsilon_{s}$ is the surface emissivity between 3 and $100 \mu \mathrm{m}, \sigma$ is Stephan-Boltzmann's constant and $T_{s}$ is the surface 
radiometric temperature. Broadband emissivity $\varepsilon_{s}$ is calculated from NDVI:

$$
\varepsilon_{s}=1.009+0.0047 \ln (N D V I)
$$

Soil heat flux is expressed as a fraction of net radiation, this fraction being a function of surface radiometric temperature, instantaneous albedo and daily value of albedo $\overline{\alpha_{s}}$ :

$$
\frac{G_{0}}{R_{n}}=\frac{T_{s}}{\alpha_{s}}\left(0.0032 \overline{\alpha_{s}}+0.0062{\overline{\alpha_{s}}}^{2}\right)\left(1-0.978 N D V I^{4}\right)
$$

\subsection{Estimating the convective fluxes}

Latent heat flux $L E$ is computed as the residue of surface energy budget:

$$
L E=R_{n}-G_{0}-H
$$

where $H$ is the sensible heat flux. The convention chosen is such that $R_{n}$ is positive when directed toward the surface and $G_{0}, H, L E$, are positive when directed away from the surface. Sensible heat flux $H\left(z_{0 h}, z\right)$ between the surface and a level $z$ is evaluated using a bulk resistance approach:

$$
H\left(z_{0 h}, z\right)=\rho_{a} C_{p} \frac{T_{s}-T_{a}(z)}{r_{a h}\left(z_{0 h}, z\right)}
$$

where $\rho_{a}$ is the air density, $C_{p}$ is the isobaric specific heat, $T_{a}$ is the air potential temperature and $z_{0 h}$ is the scalar roughness for heat. The bulk or aerodynamic resistance for the layer between $z_{0 h}$ and $z$ is defined as:

$$
r_{a h}\left(z_{0 h}, z\right)=\frac{1}{k u_{*}}\left[\ln \left(\frac{z-d}{z_{0 h}}\right)-\Psi_{h}\left(z, L_{M O}\right)\right]
$$

where $k$ is the Von Karman's constant, $z_{0 h}$ is the roughness length for heat, $d$ is the displacement height. The friction velocity $u_{*}$ is given by:

$$
u_{*}=\frac{k u(z)}{\ln \left(\frac{z-d}{z_{0 m}}\right)-\Psi_{m}\left(z, L_{M O}\right)}
$$


where $u(z)$ is the wind speed at level $z$ and $z_{0 m}$ is the roughness length for momentum. The stability correction functions for wind and temperature $\Psi_{m}\left(z, L_{M O}\right)$ and $\Psi_{h}\left(z, L_{M O}\right)$ can be described as proposed by [7] considering both stable and unstable conditions. The Monin-Obukhov $L_{M O}$ length is given by:

$$
L_{M O}=-\frac{\rho_{a} C_{p} u_{*}^{3}}{k g H}\left(\frac{T_{s}+T_{a}(z)}{2}\right)
$$

where parameters $g$ and $k$ are gravity acceleration and Von Karman's constant respectively. The mean value of $T_{s}$ and $T_{a}(z)$ represents the air temperature of the layer between $z_{0 h}$ and $z$.

The roughness length for heat $z_{0 h}$ is set to $0.1 \times z_{0 m}$, which corresponds to a $k B^{-1}$ value of 2.3. The roughness length for momentum is deduced from NDVI:

$$
z_{0 m}=\exp (-6.665+6.38 N D V I)
$$

\subsubsection{Estimating the wind speed at the atmospheric reference level}

A illustration of the aggregation scheme is given in Figure 10. The aerodynamic resistance $r_{a h, d r y}\left(z_{b}\right)$ of the effective layer between surface and blending height (set to $100 \mathrm{~m}$ above the surface) is estimated inverting the sensible heat flux expression:

$$
r_{a h, d r y}\left(z_{b}\right)=\rho_{a} C_{p} \frac{T_{s, d r y}-T_{a}\left(z_{b}\right)}{H_{d r y}}
$$

where $T_{s, d r y}$ and $H_{d r y}$ are the mean value over dry areas of respectively surface temperature $T_{s}$ and sensible heat flux $H=R_{n}-G_{0}$. The air potential temperature at blending height $T_{a}\left(z_{b}\right)$ is given by radiosonde. Next, friction velocity $u_{*, d r y}$ and Monin-Obukhov length $L_{M O, d r y}$ of the layer are deduced solving the following system:

$$
\left\{\begin{array}{l}
\mathbf{L}_{\mathbf{M O}, \mathbf{d r y}}=-\frac{\rho_{a} C_{p} \mathbf{u}_{*, \mathbf{d r y}}{ }^{3}}{k g H_{d r y}}\left(\frac{T_{s, d r y}+T_{a}\left(z_{b}\right)}{2}\right) \\
\mathbf{u}_{*, \mathbf{d r y}}=\frac{1}{r_{a h, d r y}\left(z_{b}\right)}\left[\ln \left(\frac{z_{b}}{z_{0 h, d r y}}\right)-\Psi_{h}\left(z_{b}, \mathbf{L}_{\mathbf{M O}, \mathbf{d r y}}\right)\right]
\end{array}\right.
$$


The effective roughness lengths are computed using quadratic averages. Finally, a mean value over the whole site of wind speed at atmospheric reference level $z_{a}$ $<u\left(z_{a}\right)>$ is computed:

$$
<u\left(z_{a}\right)>=\frac{u_{*, d r y}}{k}\left[\ln \left(\frac{z_{a}}{z_{0 m, d r y}}\right)-\Psi_{m}\left(z_{a}, L_{M O, d r y}\right)\right]
$$

[Figure 10 about here.]

\subsubsection{Air temperature and sensible heat flux}

The slope and offset of the linear relation between air and surface temperatures are estimated inverting the sensible heat flux expression over wet areas $\left(T_{s}=T_{a}\right)$ and dry areas $\left(H=R_{n}-G_{0}\right)$. This leads to express the difference as

$$
T_{s}-T_{a}\left(z_{a}\right)=\frac{T_{s}-T_{s, \min }}{T_{s, \max }-T_{s, \min }}\left[\frac{\left(R_{n}-G_{0}\right) r_{a h}\left(z_{a}\right)}{\rho_{a} C_{p}}\right]_{T_{s, \max }}
$$

where $T_{s, \min }$ and $T_{s, \max }$ are surface temperature over wet and dry areas respectively. This approach yields to a system of three unknowns and three equations which resolution provides an estimate of both air temperature and sensible heat flux:

$$
\left\{\begin{array}{l}
\mathbf{H}=f_{1}\left(\mathbf{u}_{*}, \mathbf{L}_{\mathbf{M O}}, z_{0 h}, z_{a}, T_{s, \min }, T_{s, \max }, T_{s}, \rho_{a}, C_{p}, R_{n}, G_{0}\right) \\
\mathbf{L}_{\mathbf{M O}}=f_{2}\left(\mathbf{u}_{*}, \mathbf{H}, T_{s}, T_{a}\left(z_{a}\right), g, k, \rho_{a}, C_{p}\right) \\
\mathbf{u}_{*}=f_{3}\left(\mathbf{L}_{\mathbf{M O}},<u\left(z_{a}\right)>, k, z_{0 m}, z_{a}\right)
\end{array}\right.
$$

\section{Acknowledgments}

This study was performed during a post-doctoral position funded by the ASTER project of NASA's EOS-Terra Program. Financial support was provided by EC in the frame of the WATERMED project (contract ICA3-CT-1999-00015). The Alpilles / ReSeDA project was funded by the EEC-DG XII (contract ENV4-CT960326-PL952071) and the French Programme National de Télédétection Spatiale 
and Programme National de Recherches en Hydrologie. The PolDER airborne sensor was provided by the Laboratoire d'Optique Atmosphérique, Lille, France. The authors are grateful to J.F. Hanocq (INRA / CSE, Avignon, France) and O. Hautecoeur (CESBio, Toulouse, France) for the airborne data acquisition and preprocessing; to A. Bokoye, N. Tallet and J. Hanocq (INRA / CSE, Avignon, France) for their participation to the image registration, to T. Wassenaar (INRA / CSE, Avignon, France) for his participation to the radiometric preprocessing, to O. Marloie (INRA / CSE, Avignon, France) for improving the quality of the field database, and to C. Francois (CETP, Vélizy, France) for providing the CIMEL ground based measurements. 


\section{References}

[1] Anderson M., Norman J., Diak G., Kustas W., J.R. M., A two-source time integrated model for estimating surface fluxes using thermal infrared remote sensing, Remote Sensing of Environment 60 (1997) 195-216.

[2] Bastiaanssen W., Regionalization of surface fluxes densities and moisture indicators in composite terrain, Phd thesis, 273 pp, Agricultural University Wageningen (1995).

[3] Bastiaanssen W., Menenti M., Feddes R., Holtslag A., A remote sensing surface energy balance algorithm for land (SEBAL). I: Formulation, Journal of Hydrology 212-213 (1998) 198-212.

[4] Bastiaanssen W., Pelgrum H., Wang J., Ma Y., Moreno J., Roerink G., van der Wal T., A remote sensing surface energy balance algorithm for land (SEBAL). II: Validation, Journal of Hydrology 212-213 (1998) 213-292.

[5] Becker F., Li Z., Surface temperature and emissivity at various scale: definition, measurement and related problem, Remote Sensing Reviews 12 (1995) $225-253$.

[6] Becker F., Seguin B., Determination of surface parameters and fluxes for climate studies from space observation. Methods, results, and problems, Advances in Space Research 5 (1985) 299-317.

[7] Beljaars A., Holtslag A., Flux parameterization over land surfaces for atmospheric models, Journal of Applied Meteorology 30 (1991) 327-341.

[8] Berk A., Bernstein L., Anderson G., Acharya P., Robertson D., Chetwynd J.H. amd Adler=Golden S., MODTRAN cloud and multiple scattering upgrades with application to AVIRIS, Remote Sensing of Environment 65 (1998) 367-375.

[9] Bindlish R., Kustas W., French A. N., Diak G. R., J.R. M., Influence of nearsurface soil moisture on regional scle heat fluxes: model results using microwave remote sensing data from SGP97, IEEE Transaction on Geoscience and Remote Sensing 39 (2001) 1719-1728. 
[10] Brasa-Ramos A., De Santa Olalla F., Caselles V., A.M. J., Comparison of evapotranspiration estimates by NOAA-AVHRR images and aircraft flux measurements in a semiarid region of Spain, Journal of Agricultural Engineering Research 285-294 (1998) 70.

[11] Capehart W., Carlson T., Decoupling of surface and near-surface soil water content: A remote sensing perspective, Water Resources Research 33 (1997) 1383-1395.

[12] Carlson T., Capehart W., Gillies R., A new look at the simplified method for remote sensing of daily evapotranspiration, Remote Sensing of Environment 54 (1995) 161-167.

[13] Carlson T., Rippley D., On the relation between NDVI, fractional vegetation cover and leaf area index, Remote Sensing of Environment 62 (1997) 241252.

[14] Choudhury B., Ahmed N., Idso S., Reginato R., Daughtry C., Relation between evaporation coefficients and vegetation indices studied by model simulations, Remote Sensing of Environment 50 (1994) 1-17.

[15] Courault D., Cauchy P., Clastre P., Bloser B., Analyse des variations spatiales de la temperature de l'air en fonction de l'occupation de surface, Photo Interpretation 34 (1996) .

[16] Courault D., Clastre P., Guinot J., Seguin B., Analyse des sécheresses de 1988 à 1990 en France à partir de l'analyse combinée de données satellitaires NOAA - AVHRR et d'un modèle agrométeorologique, Agronomie 14 (1994) $41-56$.

[17] Courault D., Lacarrere P., Clastre P., Lecharpentier P., Jacob F., Estimation of surface fluxes using remote sensing data and the MESONH model on the ALPILLES area, in: Remote sensing and Hydrology Symposium, Montpellier, France, 2001, Submitted.

[18] Deschamps P., Bréon F., Leroy M., Podaire A., Bricaud A. Buriez J., Sèze G., The PolDER mission : instrument characteristics and scientific objectives, IEEE Transactions on Geoscience and Remote Sensing 32 (1994) 598-615. 
[19] Diak G., Whipple M., Improvement to models and methods for evaluating the land surface energy balance and 'effective' roughness using radiosonde reports and satellite-measured 'skin' temperature data, Agricultural and Forest Meteorology 63 (1993) 189-218.

[20] François C., Ottlé C., Olioso A., Prévot L., Bruguier N., Ducros Y., Conversion of 400 - $1100 \mathrm{~nm}$ vegetation albedo measurements into total shortwave broadband albedo using a canopy radiative transfer model, Agronomie (2002) Accepted.

[21] Gillies R., Carlson T., Cui J., Kustas W., Humes K., Verification of the 'triangle' method for obtaining surface soil water content and energy fluxes from remote measurements of the Normalized Vegetation Index NDVI and surface radiant temperature, International Journal of Remote Sensing 18 (1997) 3145-3166.

[22] Gu X.-F., Jacob F., Hanocq J.-F., Yu T., Liu Q., Prévot L., Tian G., Li X., Tallet N., Measuring and analysing the thermal infrared emission directionality over crop canopies with an airborne wide-angle thermal IR camera, Agronomie (2002) Submitted.

[23] Hafeez M., Chemin Y., Evaporation estimation using TERRA/ASTER sensor: a case study in District 1 of UPRISS, Central Luzon, Philippines, Canadian Journal of Remotes Sensing 2 (2002) Submitted.

[24] Hamimed A., Mederbal K., Khaldi A., Utilisation des donneées satellitaires TM de Landsat pour le suivi de l'état hydrique d'un couvert végétal dans les conditions semi-arides en Algérie, Télédétection 2 (2001) 29-38.

[25] Hasager C., Olioso A., Jacob F., Scaling Surface Heat Flux from Eddy Correlation Data to NOAA AVHRR Resolution with a Microscale Flux Aggregation Model for the Alpilles Experiment in France, in: Remote sensing and Hydrology 2001, Proceedings of a symposium held at Montpellier, France, October 2001., 2001.

[26] Horiguchi I., Tani H., Motoki T., Accurate estimation of $1.5 \mathrm{~m}$-height air temperature by MS IR data, in: Proceedings of the 24th International Symposium on Remote Sensing of Environment, Rio de Janeiro, May 1991, 1992, pp. 301-307. 
[27] Humes K., Kustas W., Goodrich D., Spatially distributed sensible heat flux over a semiarid watershed. Part I : use of radiometric surface temperatures and a spatially uniform resistance, Journal of Applied Meteorology 36 (1997) 281-292.

[28] Inframetrics, INFRAMETRICS MODEL 760, Operator's manual, Inframetrics Incorporation, 1991.

[29] Jacob F., Gu X., Hanocq J.-F., Baret F., Atmospheric corrections of single broadband channel and multidirectional airborne thermal infrared data. Application to the ReSeDA Experiment, International Journal of Remote Sensing (2002) Accepted.

[30] Jacob F., Olioso A., Derivation of diurnal courses of albedo and reflected solar radiation from PolDER data, Journal of Geophysical Research (2001) Submitted.

[31] Jacob F., Olioso A., Weiss M., Baret F., Hautecoeur O., Mapping short-wave albedo of agricultural surfaces using airborne PolDER data, Remote Sensing of Environment 80 (2002) 36-46.

[32] Jacob F., Weiss M., Olioso A., French A., Assessing the narrowband to broadband conversion to estimate visible, near infrared and shortwave apparent albedo from airborne PolDER data, Agronomie (2002) Accepted.

[33] Kustas W., Humes K., Norman J., Moran M., Single and dual source modeling of surface energy fluxes with radiometric surface temperature, Journal of Applied Meteorology 35 (1996) 110-121.

[34] Kustas W., Moran M., Humes K., Stannard D., Pinter P., Hipps L., Swiatek E., Goodrich D., Surface energy balance estimates at local and regional scales using optical remote sensing from an aircraft platform and atmospheric data collected over semiarid rangelands, Water Resources Research 30 (1994) 12411259 .

[35] Kustas W., Moran M., Jackson R., Gay L., Duell L., Kunkel K., Matthias A., Instantaneous and daily values of the surface energy balance over agricultural fields using remote sensing and a reference field in a arid environment, Remote Sensing of Environment 32 (1990) 125-141. 
[36] Kustas W., Perry E., Doraiswamy P., Moran M., Using satellite remote sensing to extrapolate evapotranspiration estimates in time and space over a semiarid rangeland basin, Remote sensing of Environment 49 (1994) 275-286.

[37] Lagouarde J.-P., Jacob F., Gu X.-F., Olioso A., Bonnefond J.-M., Kerr Y., McAnneney K., Irvine M., Spatialization of sensible heat flux over a heterogeneous landscape, Agronomie (2002) Accepted.

[38] Leroy M., Hautecoeur O., Directional parameters, hemispherical reflectances and angle-corrected NDVIs derived at global scale by the spaceborne PolDER, in: Proceedings of Alps 1999 conference, Méribel, France, January 18-22, 'Land surface' session (Ed. CNES), 1999, pp. 1-4.

[39] Mecikalski J., Diak G., Anderson M., Norman J., Estimating fluxes on continental scales using remotely-sensed data in an atmospheric-land exchange model, Journal of Applied Meteorology 38 (1999) 1352-1369.

[40] Menenti M., Bastiaanssen W., van Eick D., Determination of hemispherical reflectance with Thematic Mapper data, Remote Sensing of Environment 28 (1989) 327-337.

[41] Moran M., Jackson R., Raymond L., Gay L., Slater P., Mapping surface energy balance components by combining Landsat Thematic Mapper and ground based meteorological data, Remote Sensing of Environment 30 (1989) $77-87$.

[42] Moran M., Kustas W., Vidal A., Stannard D., Blanford J., Nichols W., Use of ground-based remotely sensed data for surface energy balance evaluation of a semiarid rangeland, Water Resources Research 30 (1994) 1339-1349.

[43] Noilhan J., Lacarrere P., GCM grid-scale evaporation from mesoscale modeling, Journal of Climate 8 (1995) 206-223.

[44] Norman J., Kustas W., Humes K., Source approach for estimating soil and vegetation energy fluxes in observations of directional radiometric surface temperature, Agricultural and Forest Meteorology 77 (1995) 263-293.

[45] Norman J., Kustas W., Prueger J., Diak G. R., Surface flux estimation using radiometric temperature: a dual-temperature-difference method to minimize measurement errors, Water Resources Research 36 (2000) 2263-2274. 
[46] Olioso A., Estimating the difference between brightness and surface temperatures for a vegetal canopy, Agricultural and Forest Meteorology 72 (1995) $237-242$.

[47] Olioso A., Braud I., Chanzy A., Courault D., Demarty J., Kergoat L., Lewan L., Ottlé C., Prévot L., Zhao W., Calvet J., Cayrol P., Jongschaap R., Moulin S., Noilhan J., Wigneron J.-P., SVAT modeling over the Alpilles-ReSeDA experiment: comparison of SVAT models, first results on wheat, Agronomie (2002) Submitted.

[48] Olioso A., Braud I., Chanzy A., Ducros Y., Gaudu J., Gonzales-Soza E., Lewan L., Marloie O., Ottlé C., Prévot L., Autret H., Bethenod I., Bonnefond J., Brugier N., Calvet J., Chauki H., Goujet R., Jongschaap R., Kerr Y., Lagouarde J., Laurent J., McAnneney J., Moulin S., Thony J., Weiss M., Wigneron J.-P., SVAT modeling over the Alpilles-ReSeDA experiment: experimental setup for monitoring energy and mass transfers, Agronomie (2002) Submitted.

[49] Olioso A., Chauki H., Courault D., Wigneron J., Estimation of evapotranspiration and photo-synthesis by assimilation of remote sensing data into SVAT models, Remote Sensing of Environment 68 (1999) 341-356.

[50] Olioso A., Jacob F., Hadjar D., Lecharpentier P., Hasager C., Spatial distribution of evapotrranspiration and aerodynamic roughness from optical remote sensing, in: Worshop on landscape heterogeneity and aerodynamic roughness: modeling and remote sensing perspectives, Octobre 2001, Anvers, Belgique, 2001.

[51] Olioso A., Prévot L., Baret F., Chanzy A., Braud I., Autret H., Baudin F., Bessemoulin P., Bethenod O., Blamont D., Blavoux B., Bonnefond J., Boubkraoui S., Bouman B., Bruguier N., Calvet J., Caselles V., Chauki H., Clevers J., Coll C., Company A., Courault D., Dedieu G., Degenne P., Delécolle R., Denis H., Desprats J., Ducros Y., Dyer D., Fies J., Fischer A., Francois C., Gaudu J., Gonzalez E., Gouget R., Gu X., Guérif M., Hanocq J., Hautecoeur J., Haverkamp R., Hobbs S., Jacob F., Jeansoulin R., Jongschaap R., Kerr Y., King C., Laborie P., Lagouarde J., Laques A., Larcena D., Laurent G., Laurent J., Leroy M., McAneney J., Macelloni G., Moulin S., Noil- 
han J., Ottlé C., Paloscia S., Pampaloni P., Podvin T., Quaracino F., Roujean J., Rozier C., Ruisi R., Susini C., Taconet O., Tallet N., Thony J., Travi Y., Van Leewen H., Vauclin M., Vidal-Madjar D., Vonder O., Weiss M., Wigneron J., Spatial aspects in the Alpilles-ReSeDA project, in: Scaling and modeling in forestry: application in remote sensing and GIS, Ed. D.Marceau, Université de Montréal, Québec, 1998, pp. 92-102.

[52] Olioso A., Taconet O., Ben Mehrez M., Estimation of heat and mass fluxes from IR brightness temperature, IEEE Transactions on Geoscience and Remote Sensing 34 (1996) 1184-1190.

[53] Ottlé C., Vidal-Madjar D., Assimilation of soil moisture inferred from infrared remote sensing in a hydrological model over the HAPEX-MOBILHY region, Journal of Hydrology 158 (1994) 241-264.

[54] Prévot L., Baret F., Chanzy A., Olioso A., Wigneron J., Autret H., Baudin F., Bessemoulin P., Bethenod O., Blamont D., Blavoux B., Bonnefond J., Boubkraoui S., Bouman B., Braud I., Bruguier N., Calvet J., Caselles V., Chauki H., Clevers J., Coll C., Company A., Courault D., Dedieu G., Degenne P., Delécolle R., Denis H., Desprats J., Ducros Y., Dyer D., Fies J., Fischer A., Francois C., Gaudu J., Gonzalez E., Gouget R., Gu X., Guérif M., Hanocq J., Hautecoeur J., Haverkamp R., Hobbs S., Jacob F., Jeansoulin R., Jongschaap R., Kerr Y., King C., Laborie P., Lagouarde J., Laques A., Larcena D., Laurent G., Laurent J., Leroy M., McAneney J., Macelloni G., Moulin S., Noilhan J., Ottlé C., Paloscia S., Pampaloni P., Podvin T., Quaracino F., Roujean J., Rozier C., Ruisi R., Susini C., Taconet O., Tallet N., Thony J., Travi Y., Van Leewen H., Vauclin M., Vidal-Madjar D., Vonder O., Weiss M., Assimilation of multi-sensor and multi-temporal remote sensing data to monitor vegetation and soil: the Alpilles ReSeDA project, in: IGARSS'98 International Geoscience and Remote Sensing Symposium, IEEE, Institute of Electrical and Electronics Engineers, Piscataway (USA), Sensing and managing the environment (Ed. L Tsang), volume 5, 1998, pp. 2399-2401.

[55] Prévot L., Champion I., Guyot G., Estimating surface soil moisture and leaf area index of a wheat canopy using a dual-frequency ( $\mathrm{C}$ and $\mathrm{X}$ bands) scatterometer, Remote Sensing of Environment 46 (1993) 331-339. 
[56] Rahman H., Dedieu G., SMAC : a Simplified Method for the Atmospheric Correction of satellite measurements in the solar spectrum, International Journal of Remote Sensing 16 (1994) 123-143.

[57] Schmugge T., Hook S., Coll C., Recovering Surface Temperature and Emissivity from Thermal Infrared Multispectral Data, Remote Sensing of Environment 65 (1998) 121-131.

[58] Schmugge T., Kustas W., Humes K., Monitoring Land Surface Fluxes Using ASTER Observations, IEEE Transactions on Geoscience and Remote Sensing 36 (1998) 1421-1430.

[59] Seguin B., Becker F., Phulpin T., Gu X., Guyot G., Kerr Y., King C., Lagouarde J., Ottlé C., Stoll M., Tabbagh T., Vidal A., IRSUTE: A minisatellite project for land surface heat flux estimation from field to regional scale, Remote Sensing of Environment 68 (1999) 357-369.

[60] Seguin B., Lagouarde J., Steinmetz S., Vidal A., Monitoring crop water use in irrigated areas with thermal infrared remote sensing data, in: Remote sensing evaluation and management of irrigation, Massimo Menenti Ed., BCRS, 1989, pp. 90-55.

[61] Song J., Gao W., An improved method to derive surface albedo from narrowband AVHRR satellite data: narrow-band to broadband conversion, Journal of Applied Meteorology 38 (1999) 239-249.

[62] Stannard D., Blanford J., Kustas W., Nichols W., Amer S., Schmugge T., Wetlz M., Interpretation of surface fluxes measurements in heterogeneous terrain during the Monsoon ' 90 experiment, Water Resources Research 30 (1994) 1227-1239.

[63] Su Z., Menenti M., Pelgrum H., van den Hurk B., Bastiaanssen W., Remote sensing of land surface fluxes for updating numerical weather predictions, in: Operational Remote Sensing for Sustainable Development, Nieuwenhuis, Vaughan and Molenaar Eds, 1999 Balkema, Rotterdam, 1998.

[64] Su Z., Pelgrum H., Menenti M., Aggregation effects of surface heterogeneity in land surface processes, in: Hydrology and Earth Science System (Eds. Z Su, M Menenti), volume 3, 1999, pp. 549-563. 
[65] van de Griend A., Owe M., On the relationship between thermal infrared emissivity and the Normalized Difference Vegetation Index for natural surfaces, International Journal of Remote Sensing 14 (1993) 1119-1131.

[66] van den Hurk B., Bastiaanssen W., Pelgrum H., van Meijgaard E., A new methodology for assimilation of initial soil moisture fields in weather prediction models using METEOSAT and NOAA data, Journal of Applied Meteorology 36 (1997) 1271-1283.

[67] Wanner W., Li X., Strahler A., On the derivation of kernels for kernel-driven models of bidirectional reflectance, Journal of Geophysical Research 100 (1995) 21077-21089.

[68] Weiss M., Baret F., Evaluation of Canopy Biophysical Variable Retrival Performances from the Accumulation of Large Swath Satellite Data, Remote Sensing of Environment 70 (1999) 293-306.

[69] Weiss M., Baret F., Leroy M., Bégué A., Hautecoeur O., Santer R., Hemispherical reflectance and albedo estimate from the accumulation of acrosstrack sun-synchronous satellite data, Journal of Geophysical Research 104 (1999) 22221-22232.

[70] Zhan X., Kustas W., Humes K., An intercomparison study on models of sensible heat flux over partial canopy surfaces with remotely sensed surface temperature, Remote Sensing of Environment 58 (1996) 242-256. 


\section{List of Figures}

1 Evolution of radiometric temperature versus albedo over the ReSeDA experimental site on March, 12, 1997. . . . . . . . . . 36

2 Comparison between SEBAL simulations and field measurements of wind speed at atmospheric reference level. . . . . . . . . . . 37

3 Comparison between SEBAL simulations and field measurements of air temperature. . . . . . . . . . . . . . . . 38

4 Comparison between SEBAL simulations and field measurements of net radiation. . . . . . . . . . . . . . . . . . 39

5 Comparison between SEBAL simulations and field measurements of soil heat flux. . . . . . . . . . . . . . . . . . 4 40

6 Comparison between SEBAL simulations and field measurements of the difference between net radiation and soil heat flux. . . . . . 41

7 Comparison between SEBAL simulations and field measurements of sensible heat flux. . . . . . . . . . . . . . . . . .

8 Comparison between SEBAL simulations and field measurements of latent heat flux. . . . . . . . . . . . . . . . . . .

9 Map of 45 minute averaged evapotranspiration (LE) over the ReSeDA experimental on April, 10, 1997 at a 20 m spatial resolution.

10 Illustration of the aggregation scheme used to compute wind speed. The aerodynamic properties of the effective layer between surface and blending height are calculated by aggregating the variables of interest over dry areas. Pixels corresponding to dry areas are allocated considering albedo values higher than the threshold value. The threshold value corresponds to the maximum temperature displayed by the temperature versus albedo diagram (Figure 1). . . . 


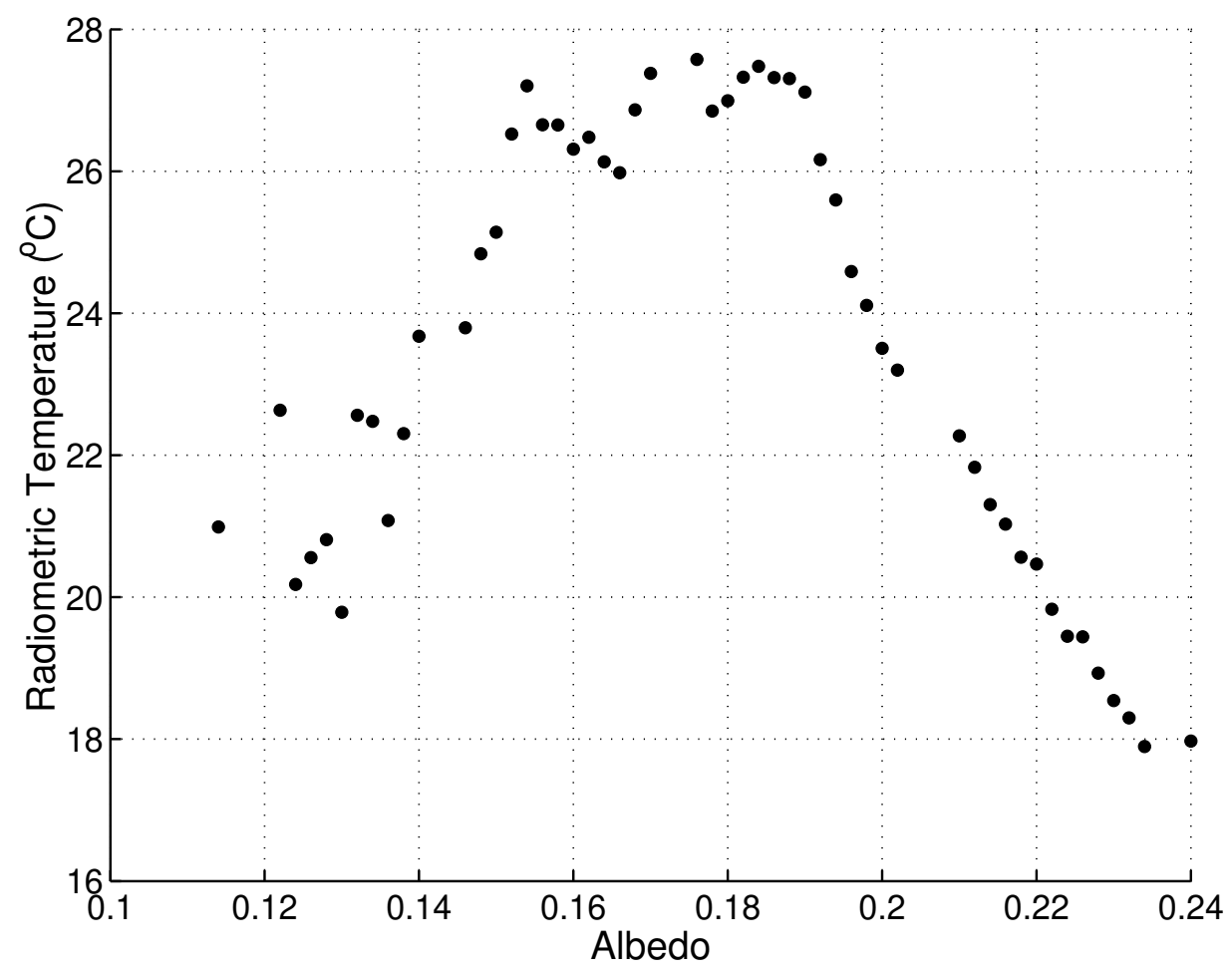

Figure 1: Evolution of radiometric temperature versus albedo over the ReSeDA experimental site on March, 12, 1997. 


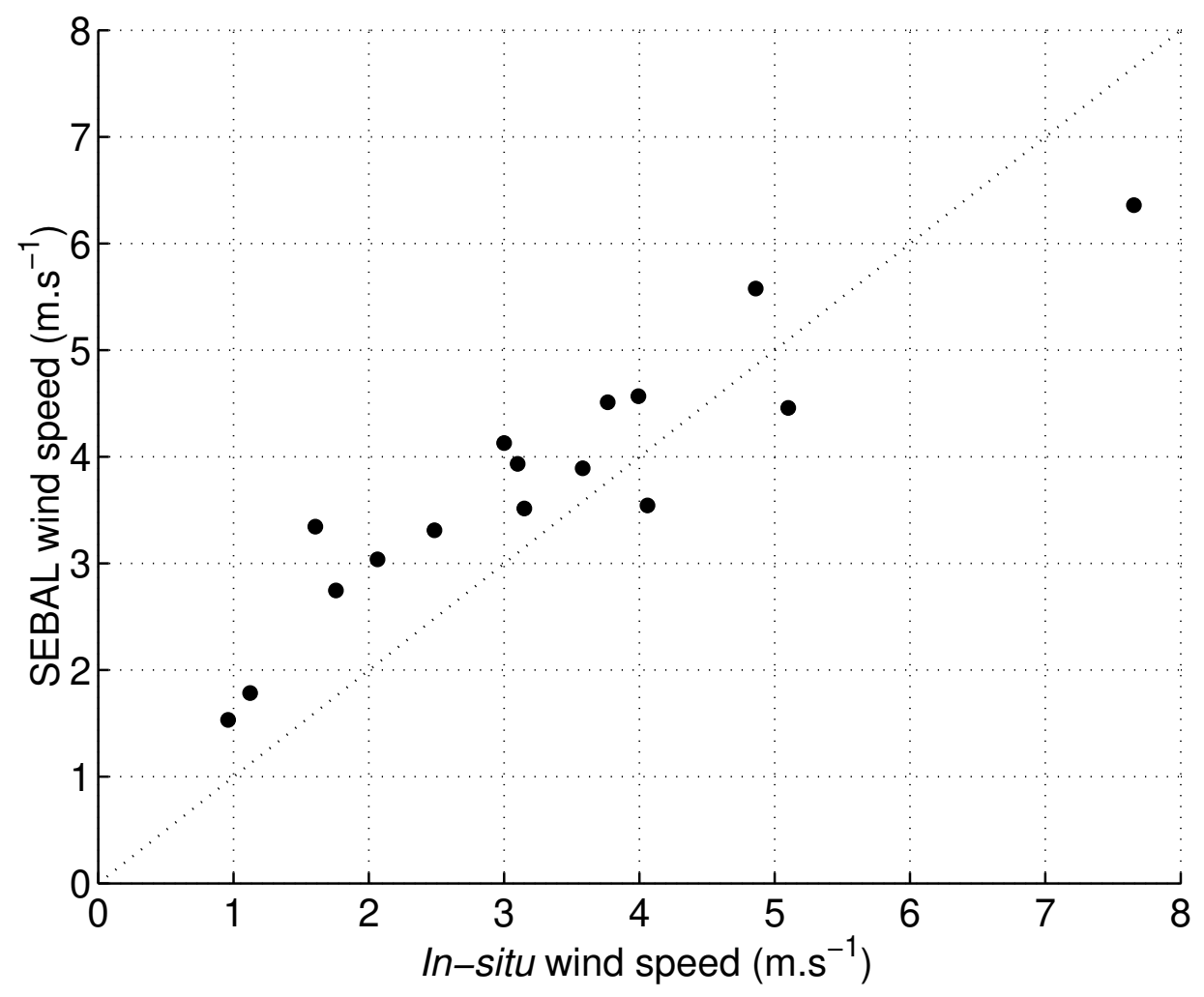

Figure 2: Comparison between SEBAL simulations and field measurements of wind speed at atmospheric reference level. 


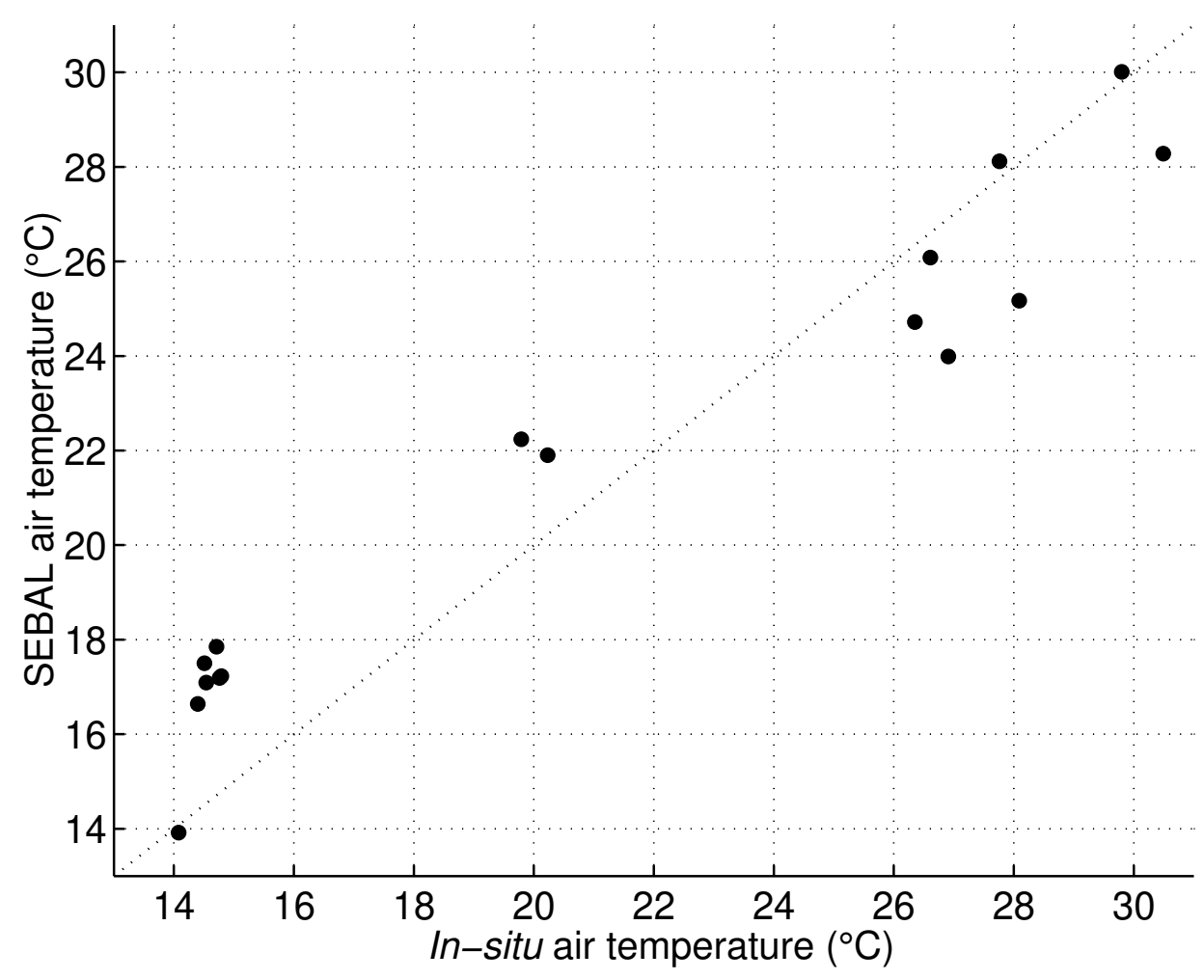

Figure 3: Comparison between SEBAL simulations and field measurements of air temperature. 


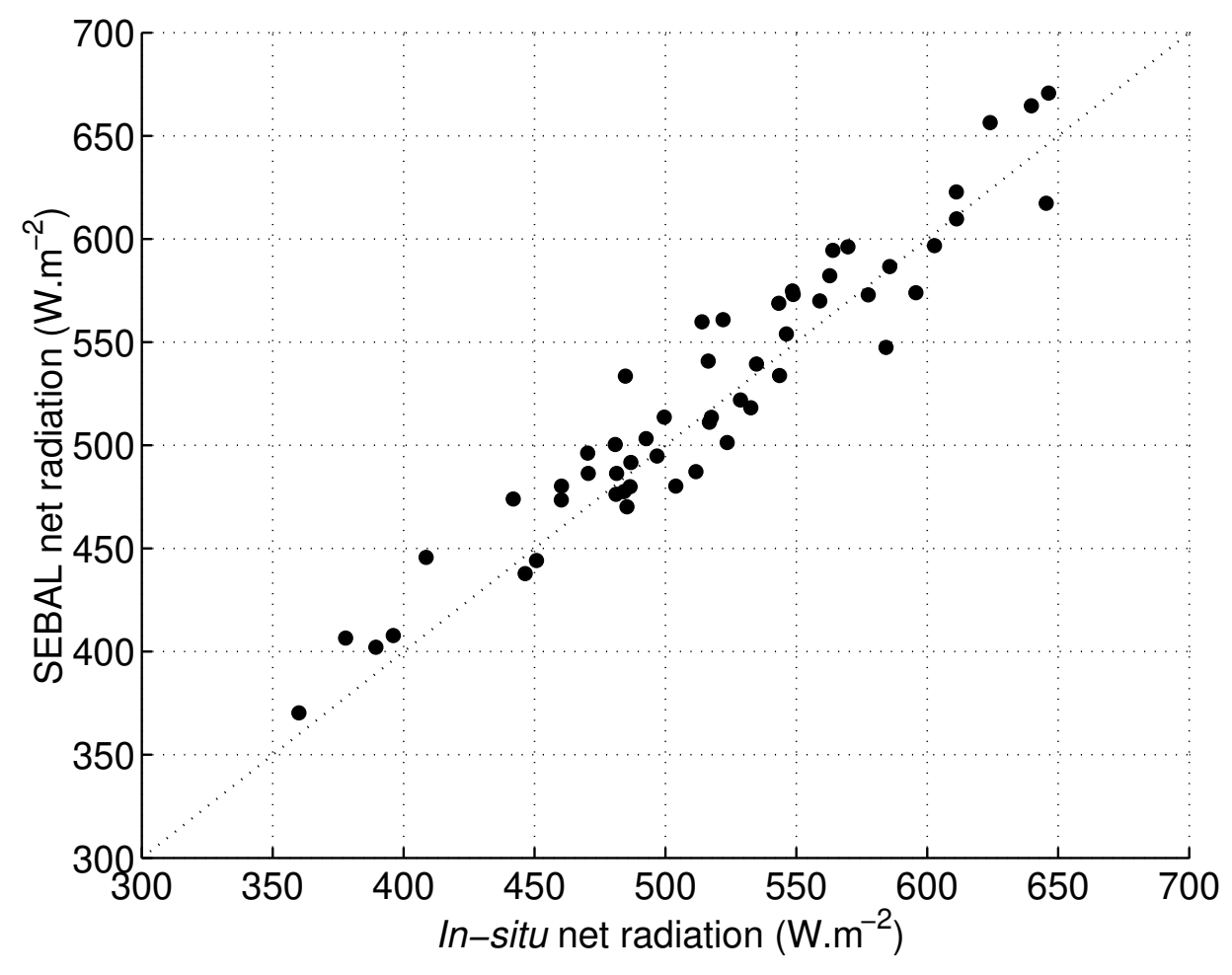

Figure 4: Comparison between SEBAL simulations and field measurements of net radiation. 


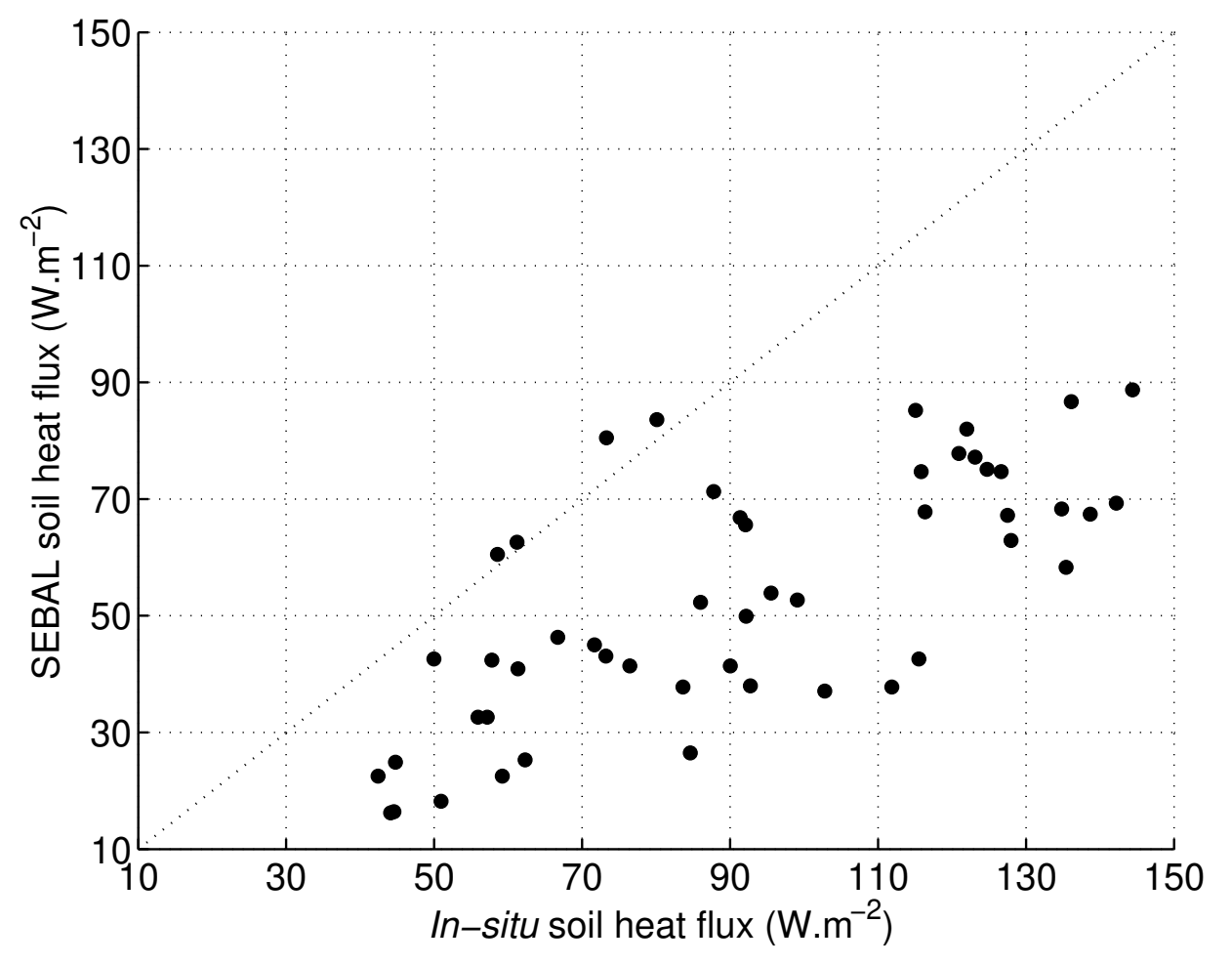

Figure 5: Comparison between SEBAL simulations and field measurements of soil heat flux. 


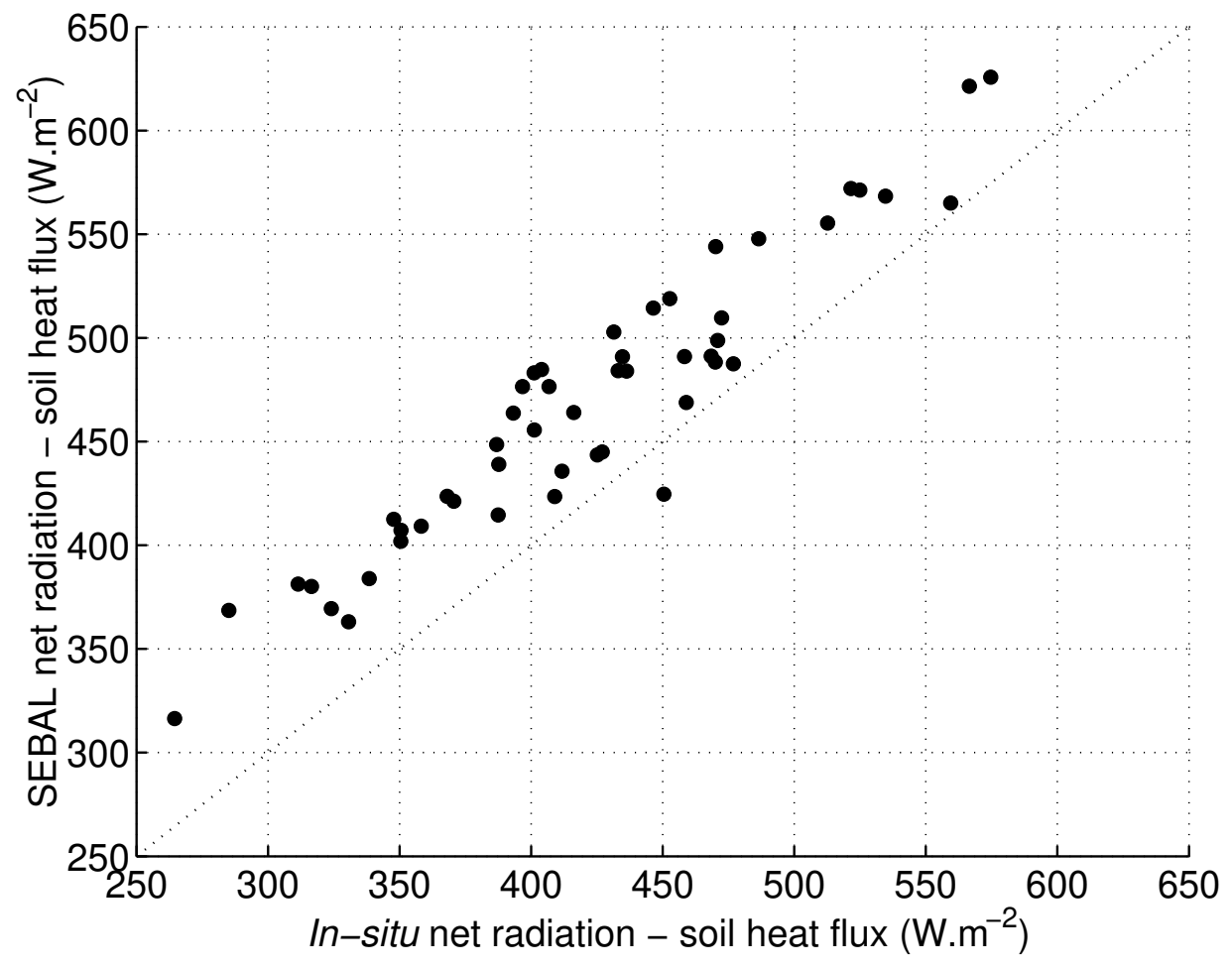

Figure 6: Comparison between SEBAL simulations and field measurements of the difference between net radiation and soil heat flux. 


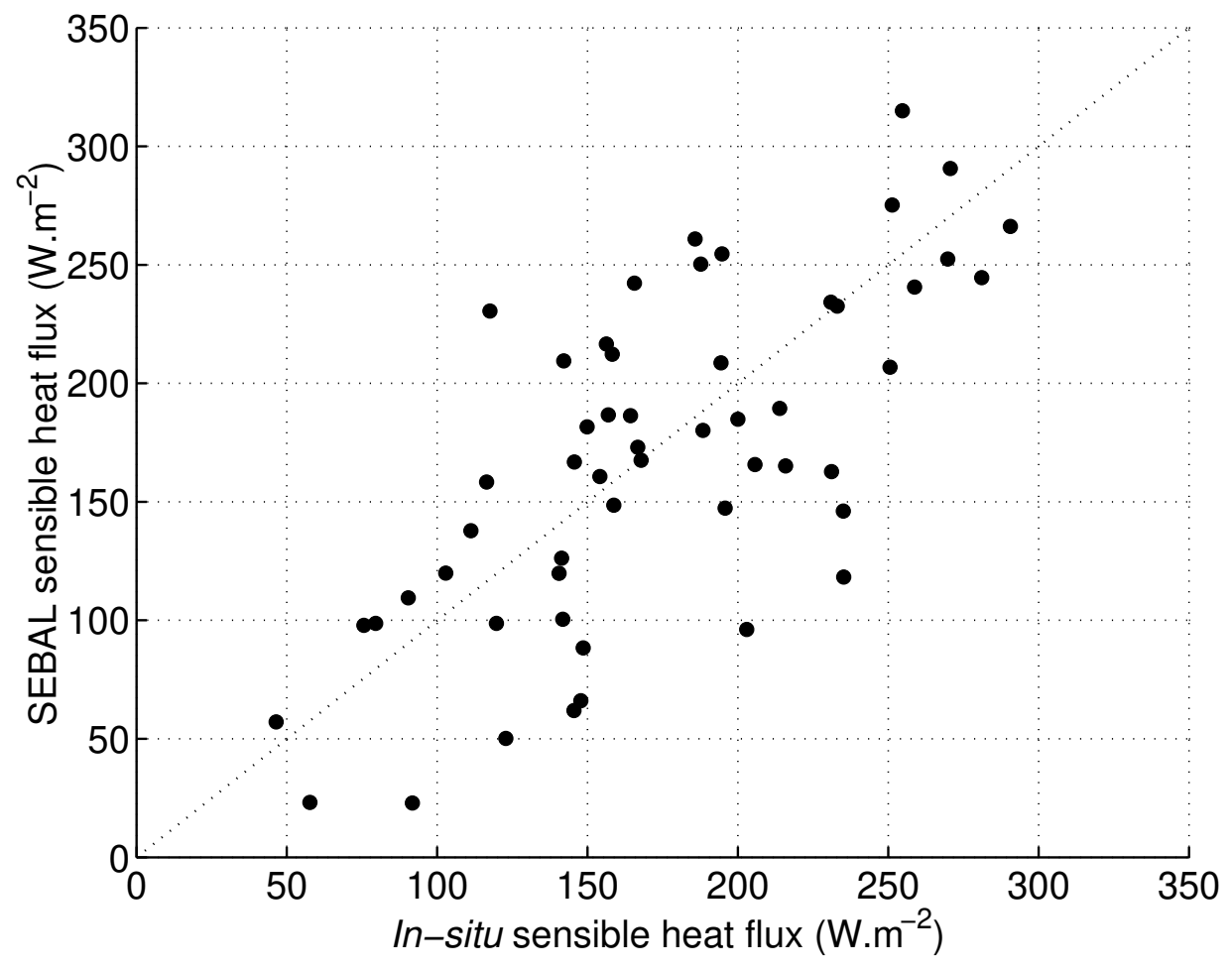

Figure 7: Comparison between SEBAL simulations and field measurements of sensible heat flux. 


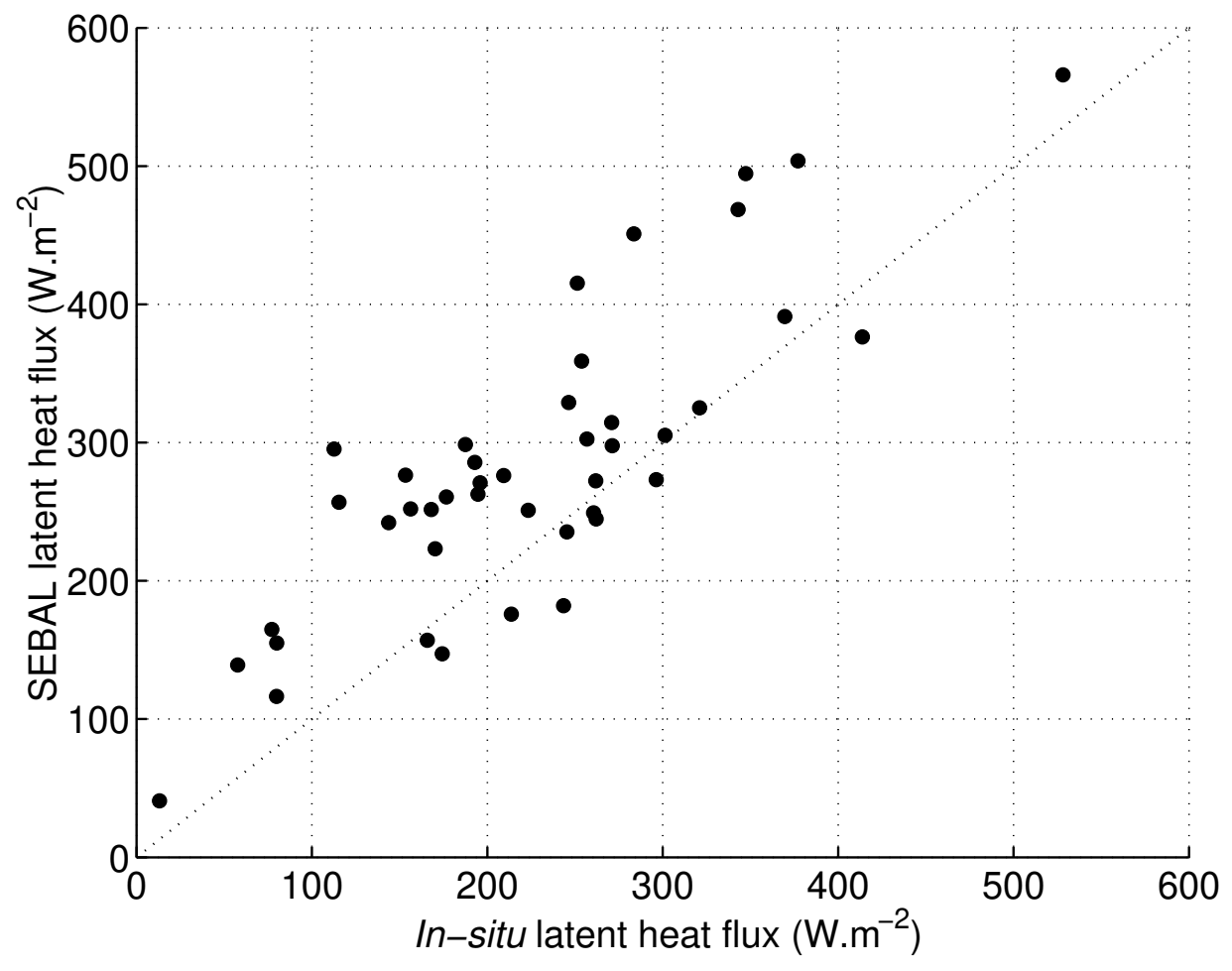

Figure 8: Comparison between SEBAL simulations and field measurements of latent heat flux. 


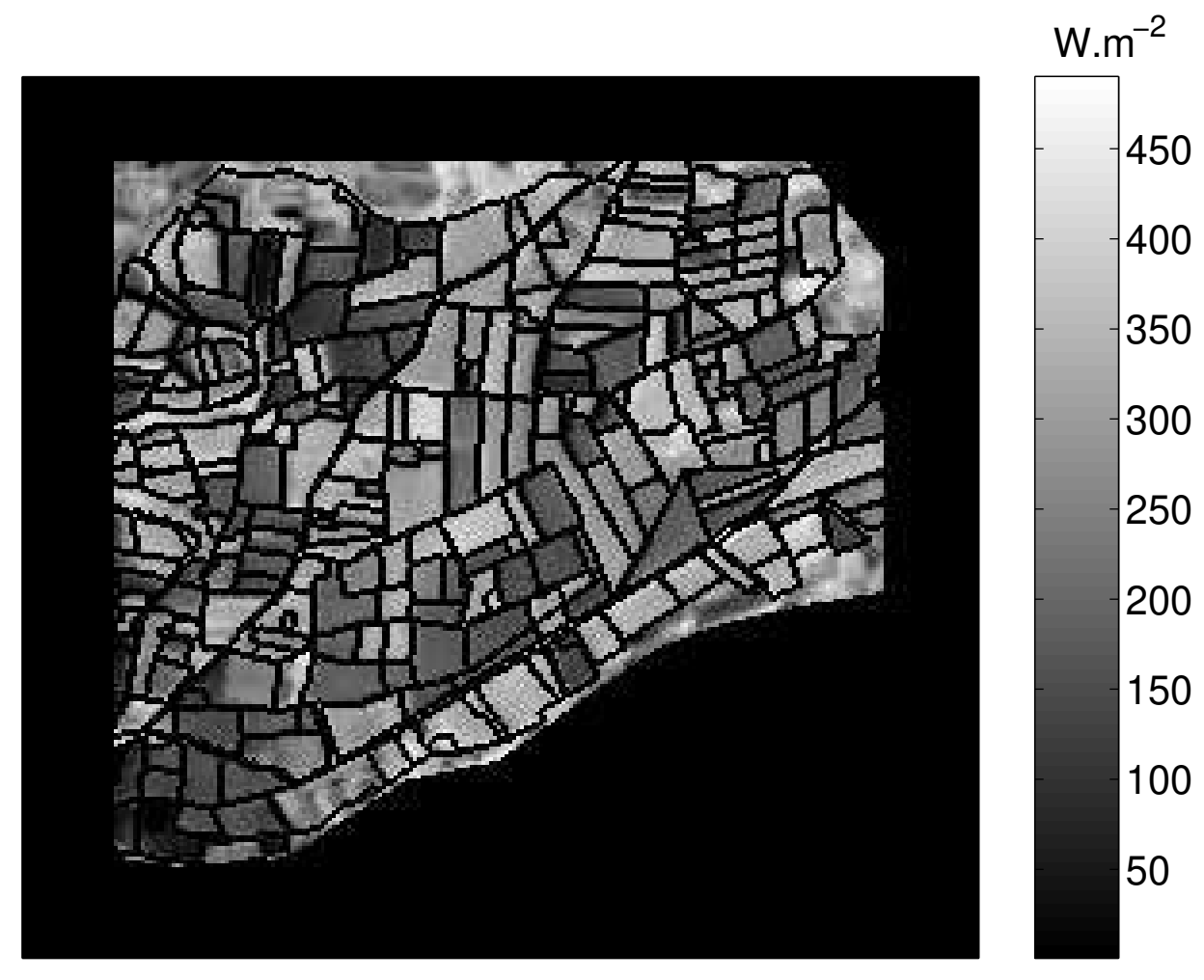

Figure 9: Map of 45 minute averaged evapotranspiration (LE) over the ReSeDA experimental on April, 10, 1997 at a $20 \mathrm{~m}$ spatial resolution. 


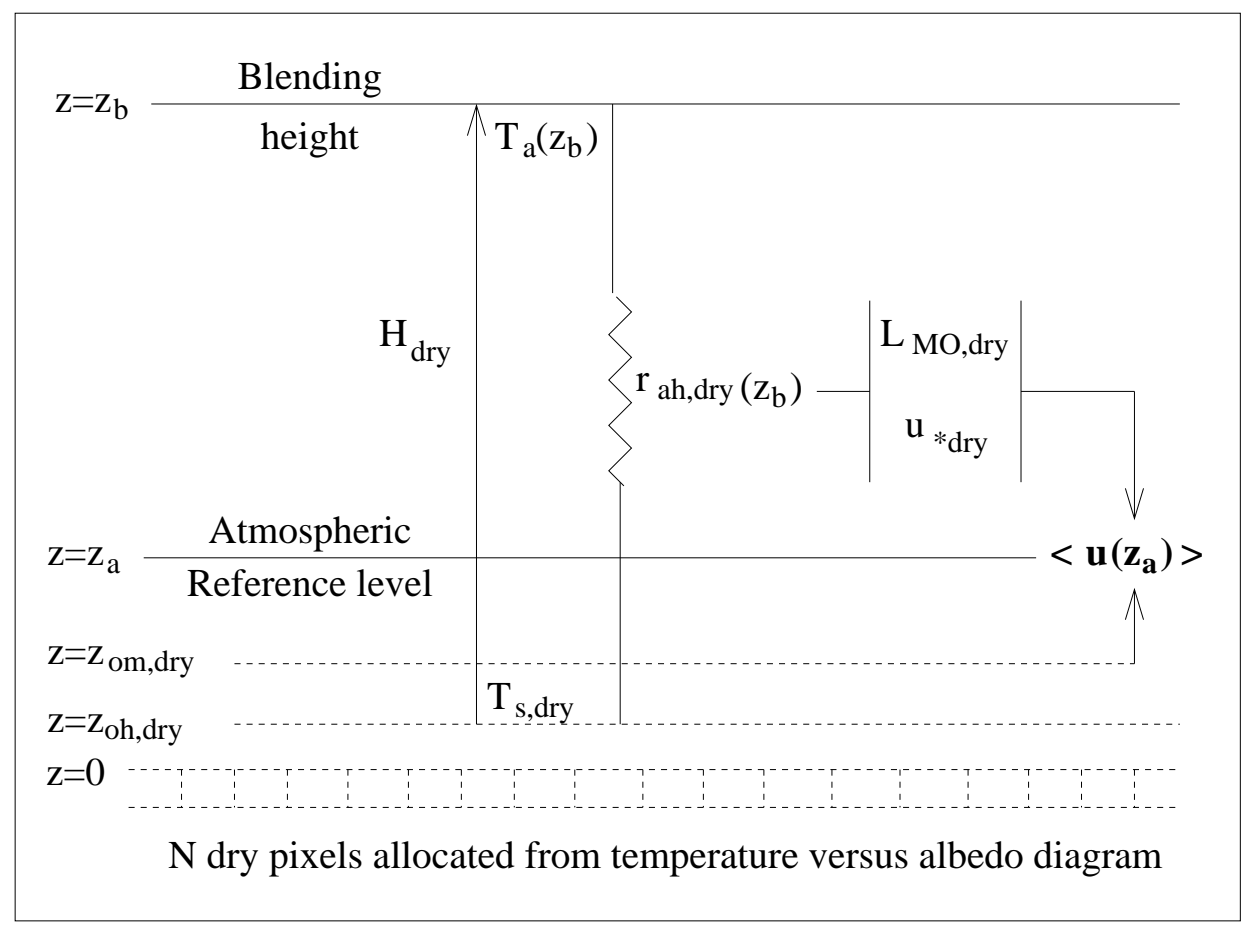

Figure 10: Illustration of the aggregation scheme used to compute wind speed. The aerodynamic properties of the effective layer between surface and blending height are calculated by aggregating the variables of interest over dry areas. Pixels corresponding to dry areas are allocated considering albedo values higher than the threshold value. The threshold value corresponds to the maximum temperature displayed by the temperature versus albedo diagram (Figure 1). 


\section{List of Tables}

1 Results of validation for SEBAL energy fluxes over the whole ReSeDA experiment. . . . . . . . . . . . . . . . 47 


\begin{tabular}{cc|cc|cc|c}
$\begin{array}{c}\text { Energy } \\
\text { Flux }\end{array}$ & $\begin{array}{c}\text { Plot } \\
\text { Number }\end{array}$ & $\begin{array}{c}\text { ARMSE } \\
\left(\mathrm{W} . \mathrm{m}^{-2}\right)\end{array}$ & $\begin{array}{c}\text { RRMSE } \\
(\%)\end{array}$ & $\begin{array}{c}\text { ABIAS } \\
\left(\mathrm{W} . m^{-2}\right)\end{array}$ & $\begin{array}{c}\text { RBias } \\
(\%)\end{array}$ & $\begin{array}{c}\text { Corr. Coef. } \\
(-)\end{array}$ \\
\hline \hline$R_{n}$ & 54 & 21.2 & 4.1 & 8 & 1.5 & 0.956 \\
\hline$G_{0}$ & 50 & 43.7 & 47.8 & -38.2 & -41.8 & 0.725 \\
\hline$R_{n}-G_{0}$ & 50 & 52 & 12.3 & 46.7 & 11.1 & 0.947 \\
\hline$H$ & 54 & 58.4 & 33.5 & -4.6 & 2.7 & 0.711 \\
\hline$L E$ & 43 & 84.8 & 33.1 & 57.8 & -22.8 & 0.829
\end{tabular}

Table 1: Results of validation for SEBAL energy fluxes over the whole ReSeDA experiment. 